\title{
TRANSFERÊNCIA CONCEITUAL: O RELATIVISMO LINGUÍSTICO NA APRENDIZAGEM DE SEGUNDA LÍNGUA
}

\author{
Renan Castro FERREIRA* \\ Isabella MOZZILLO**
}

- RESUMO: A influência de uma língua na aprendizagem de outra, ou transferência linguística, é matéria bastante investigada na área de Aquisição de Segunda Língua. Entretanto, há estudos sobre um fenômeno de transferência que ocorre no nível das categorizações conceituais e que dá suporte à hipótese da influência das línguas sobre a cognição, ou Relativismo Linguístico. Esse fenômeno, chamado transferência conceitual (JARVIS; PAVLENKO, 2010), é o objeto deste artigo, que traz uma revisão teórica da literatura sobre a questão. Primeiramente, traçamos o percurso da pesquisa sobre a influência translinguística, dos estudos iniciais, que a tomavam como algo negativo na aprendizagem de L2, até os últimos, que mostram diversos efeitos, inclusive o de facilitação. Depois, abordamos o Relativismo Linguístico, ou Hipótese Sapir-Whorf, revisitando o que foi postulado por seus autores clássicos e por pesquisadores mais recentes, que reformularam a hipótese. Finalmente, revisamos os principais modelos de representação do léxico bilíngue até o de Pavlenko (2009), que explica a transferência conceitual e aproxima o Relativismo Linguístico da Aquisição de Segunda Língua. A revisão termina com a conclusão de que a pesquisa sobre a cognição bilíngue, através da investigação da transferência conceitual, poderá revelar como as línguas que falamos influenciam a nossa cognição.

- PALAVRAS-CHAVE: Transferência conceitual. Influência Translinguística. Hipótese SapirWhorf. Relativismo Linguístico. Aprendizagem de L2. Bilinguismo.

\section{Introdução}

Qualquer pessoa que tenha tentado aprender outra língua além da(s) sua(s) língua(s) materna(s) (LM) já vivenciou situações em que uma das línguas parece afetar a compreensão ou a produção na outra. Essa "interferência", que geralmente se dá sem a consciência da pessoa, pode tanto facilitar quanto dificultar a aprendizagem ou o

\footnotetext{
Universidade Federal de Pelotas (UFPEL). Pelotas - RS - Brasil. renan.ferreira@hotmail.co.uk. ORCID: 0000-00019267-6216

*** Universidade Federal de Pelotas (UFPEL). Pelotas - RS - Brasil. isabellamozzillo@gmail.com. ORCID: 0000-00018445-9174
} 
uso da outra língua (ODLIN, 2003). Por exemplo, ela facilita e é quase inevitável quando o aprendiz encontra na língua que está aprendendo (i.e. a língua-alvo - LA) palavras que são cognatas de termos de outra língua que ele sabe (ex.: guitar em inglês e guitarra em português), mas a dificulta quando o aprendiz não consegue se livrar de um sentido presente em apenas umas das palavras de um par de cognatos (ex.: guitar = guitarra ou violão; guitarra = apenas a guitarra elétrica), levando-o a mal utilizar a outra palavra do par.

Esta influência implacável dos conhecimentos que alguém tem de uma língua sobre a compreensão ou uso de outra é bem conhecida dos estudiosos de Ensino e Aprendizagem de Segunda Língua (L2), ${ }^{1}$ que a chamam de influência translinguística (KELLERMAN; SHARWOOD-SMITH, 1986) ou transferência (ODLIN, 1989). ${ }^{2}$ De fato, também o termo interferência, utilizado acima entre aspas para ressaltar a não literalidade do seu sentido naquela frase, já foi utilizado para nomear o fenômeno em questão, numa época em que se via essa influência como algo prejudicial para a aprendizagem de línguas (FRIES, 1945; LADO, 1957).

A partir da década de 1970, no entanto, o conceito de Interlíngua, proposto em artigo homônimo pelo linguista americano Larry Selinker (SELINKER, 1972), deu novos rumos à pesquisa sobre aprendizagem de L2 e desencadeou o interesse pela investigação da transferência em vários âmbitos - primeira e principalmente em semântica, sintaxe, morfologia e fonologia, e mais tarde também nos domínios discursivo, pragmático e sociolinguístico. ${ }^{3}$

Como a maior parte dos estudos sobre a influência translinguística tem sido de cunho exploratório, muito pouco foi feito na direção de se conceber um modelo teórico que dê conta de explicar o fenômeno (JARVIS, 2000), e embora ainda haja muitas perguntas a serem respondidas sobre a natureza da transferência nos diversos níveis da estrutura linguística, os primeiros anos do século XXI viram surgir mais uma linha de investigação: alguns pesquisadores começaram a se voltar para um tipo de influência translinguística que parece se originar não das estruturas da língua-fonte, ${ }^{4}$ mas de elementos de um nível mais profundo da linguagem - o dos conceitos.

No mesmo período, mas em outras áreas - a saber, na Psicologia Experimental e na Linguística Cognitiva -, novos estudos sobre a cognição humana reavivaram o interesse da Ciência numa área de pesquisa que fora muito popular e polêmica no passado, mas que então já se encontrava praticamente defunta na Academia: a influência das línguas que falamos sobre a forma como pensamos, ou Hipótese Sapir-Whorf. A questão havia

Neste trabalho, utilizamos o termo segunda língua (L2) para nos referirmos a qualquer língua aprendida após a(s) LM, independentemente da ordem ou do contexto de aquisição.

2 No presente trabalho, utilizamos influência translinguística e transferência como sinônimos, por entendermos que, ao contrário do termo interferência, nenhum deles tem conotação negativa.

3 Para uma revisão detalhada do desenvolvimento da pesquisa sobre a influência translinguística, vide Jarvis e Pavlenko (2010).

4 O termo língua-fonte refere-se a língua de onde determinado item ou estrutura será transferido. A língua para onde esse item ou estrutura será transferido, ou a língua que sofre a influência translinguística, é chamada língua-receptora (RINGBOM, 2007). 
sido proposta academicamente nos anos 1950 (WHORF, 1956), mas o advento do Gerativismo e a falta de um método de investigação que fornecesse evidências fortes para sustentar a Hipótese acabaram marginalizando-a. Nos anos 1990, pesquisadores se dedicaram a reformular e refinar as ideias de Whorf (LUCY, 1992) e, a partir de então, alguns estudos começaram a preferir o termo Relativismo Linguístico para se referir ao tema, mas esse esforço não foi o suficiente para trazer a questão de volta ao mainstream da Ciência.

Entretanto, os novos estudos realizados no início do século XXI trouxeram dados empíricos de experimentos psicolinguísticos e neurolinguísticos, muito mais confiáveis do que os da simples observação utilizada na pesquisa de Whorf. Estudos como os de Malt, Sloman e Gennari (2003) sobre categorização de objetos e os de Boroditsky, Schmidt e Phillips (2003) sobre o gênero gramatical mostraram que as classes e categorias presentes na língua de uma pessoa podem influenciar a sua atenção ou tomada de decisões sobre certos aspectos da sua experiência no mundo, isto é, a língua pode influenciar o pensamento.

Nos últimos anos, o Relativismo Linguístico começou a interessar pesquisadores da área de estudos sobre Bilinguismo e Multilinguismo, que hoje o investigam numa subárea chamada Cognição Bilíngue (PAVLENKO, 2014). Nessa subárea, os pesquisadores também investigam quando e como a forma de pensar que é influenciada por uma língua pode afetar a aprendizagem de outra língua. Para autores como Jarvis e Pavlenko (2010), quando isso acontece, há um fenômeno de influência translinguística no nível conceitual, ou seja, em como as línguas concebem e organizam determinados domínios conceituais (ex.: gênero, movimento, cor, tempo, emoções etc.). Esse fenômeno é chamado transferência conceitual.

A natureza multifacetada da pesquisa sobre a influência translinguística, com várias áreas da Linguística e de fora dela interessadas em explorá-la, mas frequentemente investigando-a de maneira quase isolada umas das outras, faz com que nem sempre se tenha de forma clara o que está sendo investigado. O que é, de fato, transferência conceitual? O que já se descobriu sobre ela? De que maneiras ela difere da transferência linguística?

$\mathrm{Na}$ forma de uma revisão teórica da literatura, o presente trabalho revisitará as pesquisas mais importantes a respeito da influência das línguas sobre a cognição do aprendiz de L2, buscando estabelecer uma base teórica que defina transferência conceitual e a tome como o produto do Relativismo Linguístico na aprendizagem de L2.

\section{Interferência, transferência linguística ou influência translinguística}

A transferência conceitual - objeto desta revisão teórica - é, de certa forma, um dos últimos desdobramentos das pesquisas sobre a transferência. Faz-se, então, necessário que dediquemos uma parte deste trabalho para entendermos melhor o contexto em que o conceito se desenvolveu. 
De forma mais geral, a transferência pode ser definida como a influência do conhecimento prévio de uma língua sobre o conhecimento ou uso de outra (ODLIN, 1989; JARVIS; PAVLENKO, 2010). As diferentes maneiras de chamar o fenômeno interferência, transferência ou influência translinguística - refletem a abordagem teórica e o momento epistemológico da pesquisa sobre aprendizagem de L2 em que se abordou a questão.

Embora a maior parte das descobertas sobre a transferência tenha ocorrido a partir dos anos 1970 com o estabelecimento da área de estudos que hoje conhecemos como Aquisição de Segunda Língua, o interesse sobre o assunto existe há muito mais tempo. Scott Jarvis e Aneta Pavlenko, em seu livro Crosslinguistic Influence in Language and Cognition (2010), uma verdadeira antologia sobre a pesquisa da transferência, traçam um histórico sobre o tema e mencionam estudos como o de Janse (2002), no qual esse autor argumenta que o termo "bárbaros" (em grego, $\beta \alpha ́ \rho \beta \alpha \rho o \imath)$ era usado pelos gregos antigos não apenas para se referirem aos que não falavam grego, mas também aos estrangeiros que falavam "grego ruim" ou, usando a terminologia de hoje, estrangeiros que apresentavam, na sua produção de grego-L2, influência translinguística do seu conhecimento linguístico prévio, provavelmente o de suas LM.

Mesmo mais recentemente, durante a primeira metade do século XX, o fenômeno da transferência ainda era visto sob uma perspectiva negativa. Nesse período, em que noções behavioristas sobre a aprendizagem estavam em voga, linguistas e psicólogos chamavam o fenômeno em questão de interferência e argumentavam que ela seria um obstáculo para o raciocínio e que a transferência na pronúncia, por exemplo, seria causada pela "preguiça, indolência, inércia, evasão, negligência, [...] ou quaisquer outros belos sinônimos inventados para 'economia de esforço' ou 'seguir a linha de menor resistência'"’5 (JESPERSEN, 1922, p. 263, tradução nossa).

A obra Languages in Contact, de Uriel Weinreich (1953), é tida como a que de certa forma inicia a pesquisa acadêmica sobre transferência. Nesse estudo sobre o contato linguístico, o autor apresenta em detalhes vários tipos de transferência (a qual ele chama de interferência) e discute métodos para sua identificação e quantificação, assim como sua relação com outros aspectos do bilinguismo. Um dos pontos importantes desse seu trabalho é o conceito de identificações interlinguais. Como explica Odlin (1994),

[...] o que Weinreich (1953) chama de uma "identificação interlingual" ocorre sempre que um indivíduo julga que estruturas (no sentido mais amplo do termo) de duas línguas são idênticas ou pelo menos semelhantes. Tais julgamentos podem ser conscientes ou inconscientes, acurados ou inacurados, e podem ser feitos tanto por bilíngues totalmente competentes

\footnotetext{
Original: "laziness, indolence, inertia, shirking, sloth, [...] or whatever other beautiful synonyms have been invented for 'economy of effort' or 'following the line of least resistance"' (JESPERSEN, 1922, p. 263).
} 
quanto por aprendizes ainda nos estágios iniciais de aquisição de uma nova língua. ${ }^{6}$ (ODLIN, 1994, p. 29, tradução nossa).

Selinker (1972) se baseou na ideia de identificações interlinguais de Weinreich para desenvolver o conceito de Interlíngua, e o trabalho desses dois pesquisadores influenciou Kellerman (1977) no desenvolvimento do conceito de psicotipologia (a percepção do aprendiz sobre as semelhanças e diferenças entre as línguas). A partir daí, a influência do conhecimento interlinguístico na compreensão e produção do aprendiz de L2 passou a ser chamado de transferência, pois os estudos começaram a evidenciar que ela poderia levar não apenas a erros, mas também ao uso convencional da L2, às vezes até facilitando ou acelerando sua aquisição (SCHACHTER; RUTHERFORD, 1979). Descobriram também que as similaridades e diferenças entre a língua-fonte e a língua-receptora com frequência não se manifestam em erros, mas em subprodução ou superprodução de estruturas da língua-receptora (RINGBOM, 1978), ou ainda na preferência por certas estruturas ao invés de outras, como no caso do estudo de Sjöholm (1995) sobre a aprendizagem dos phrasal verbs do inglês por falantes nativos de sueco e finlandês. Esse estudo mostrou que em situações em que há opção entre verbos simples e phrasal verbs, os falantes de sueco-LM têm uma tendência a utilizar mais phrasal verbs do que os falantes de finlandês-LM, simplesmente porque sua LM, além de ser bem mais próxima do inglês do que o finlandês, também tem construções do tipo phrasal verb. Ou seja, os falantes de sueco transferem o seu conhecimento linguístico prévio, facilitando a aquisição e uso de estruturas do inglês-L2.

Ainda na década de 1980, Kellerman e Sharwood-Smith (1986) propuseram o termo influência translinguística, por entenderem que nem sempre havia transferência de conhecimentos de um sistema linguístico para outro, mas que a mera presença de certas características numa língua poderia facilitar ou dificultar a compreensão ou o uso de outra, ou seja, o conhecimento linguístico prévio influenciaria a aprendizagem de L2.

Apesar de o termo influência translinguistica ter se tornado popular nas pesquisas sobre o fenômeno (CENOZ; HUFEISEN; JESSNER, 2001; ARABSKI, 2006; JARVIS; PAVLENKO, 2010), ele não substituiu o termo transferência; hoje em dia, os dois são utilizados como sinônimos. Além disso, o termo interferência também continua a ser utilizado, particularmente em pesquisas que se concentram na investigação das transferências negativas, isto é, das influências translinguísticas que dificultam a compreensão ou produção em L2 (Fig. 1).

6 Original: “[...] what Weinreich (1953) termed as an "interlingual identification" occurs anytime an individual judges structures (in the widest sense of the term) in two languages to be identical or at least similar. Such judgements may be conscious or unconscious, they may be accurate or inaccurate, and they may be made either by fully competent bilinguals or by learners still in the earlier stages of acquiring a new language.” (ODLIN, 1994, p. 29). 
Figura 1 - Surgimento e uso dos termos "interferência", "transferência" e "influência translinguística" nos últimos 60 anos e nas publicações mais notáveis sobre o fenômeno.

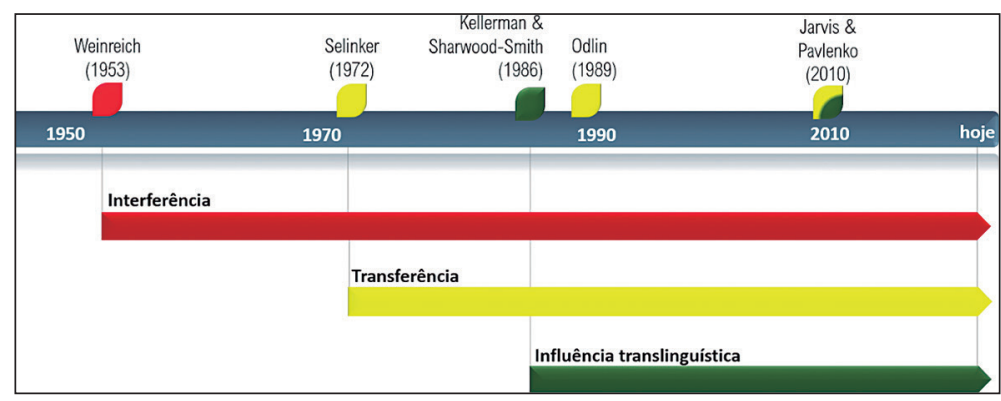

Fonte: Elaboração própria.

\section{A Hipótese Sapir-Whorf e/ou o Relativismo Linguístico}

Desde meados do século XX, a ideia de que a língua que falamos afeta a forma como pensamos e fazemos sentido da nossa experiência no mundo vem sendo estudada, defendida e criticada sob o nome de Hipótese Sapir-Whorf. Isso porque as ideias contidas nessa hipótese têm origem no trabalho de Edward Sapir (SAPIR, 2004) e, principalmente, no de seu aluno Benjamin Lee Whorf (WHORF, 1956). Entretanto, como veremos a seguir, o nome que a identifica é posterior a esses pesquisadores e, segundo alguns autores, a Hipótese como a conhecemos e estudamos hoje tem pouco a ver com as proposições originais de Sapir e Whorf.

Pesquisas e revisões bibliográficas e historiográficas sobre o Relativismo Linguístico - como também é conhecida a Hipótese Sapir-Whorf, embora haja a opinião de que se tratem de temáticas diferentes -, apontam que os primeiros argumentos cientificamente formulados sobre as relações entre língua e pensamento estão no trabalho do diplomata, filósofo e filólogo prussiano Wilhelm von Humboldt (PAVLENKO, 2014), que via as línguas como sistemas que codificam visões de mundo únicas: "cada língua desenha um círculo ao redor do povo ao qual ela adere" (HUMBOLDT, 1836 apud PAVLENKO, 2014, p. 2, tradução nossa). As ideias de Humboldt influenciaram a pesquisa de Franz Boas, que se dedicou a investigar as diferentes categorias linguísticas que parecem afetar a nossa cognição. Para Boas, nós concebemos e pensamos nossa experiência sob o efeito de conceitos que são ordenados pela nossa língua, e o fazemos sem ter consciência de tal efeito:

Original: "each language draws a circle around the people to whom it adheres" (HUMBOLDT, 1836 apud PAVLENKO, 2014, p. 2). 
As categorias da língua nos obrigam a ver o mundo organizado em certos grupos conceituais definidos que, por conta da nossa falta de conhecimento dos processos linguísticos, são tomados como categorias objetivas, e que, portanto, se impõem sobre a forma dos nossos pensamentos. (BOAS, 1920, p. 289).

Edward Sapir, aluno de Boas na Columbia University, levou essas ideias mais longe e defendeu que as categorias linguísticas dominam a nossa cognição "por causa do controle tirânico que a forma linguística tem sobre a nossa orientação no mundo" (SAPIR, 1931, p. 28). Um outro trecho de uma publicação sua é até hoje considerado um manifesto do determinismo linguístico:

Não há duas línguas que sejam suficientemente semelhantes a ponto de que se considere que representem a mesma realidade social. Os mundos nos quais diferentes sociedades vivem são mundos distintos, não meramente o mesmo mundo com diferentes rótulos fixados em si. ${ }^{9}$ (SAPIR, 1929, p. 162, tradução nossa).

Benjamin Lee Whorf, que fora aluno de Sapir na Yale University, e que também se interessava pela questão do alcance e efeito das categorias linguísticas na cognição, estudou, assim como Sapir, línguas que à época eram consideradas "exóticas”, como a língua indígena norte-americana hopi, e as línguas inuítes de povos esquimós. Suas observações e análises sobre a natureza das representações conceituais de tais línguas, em especial o argumento de que a língua hopi não teria um conceito de tempo, pelo menos não na forma de algo que possa ser dividido e subdividido, são polêmicas até hoje. Talvez a mais citada dessas considerações seja o trecho em que Whorf parece afirmar que a nossa cognição é necessariamente controlada pelas categorias disponíveis na língua que falamos:

Nós dissecamos a natureza ao longo de linhas estabelecidas pelas nossas línguas nativas. As categorias e tipos que isolamos do mundo dos fenômenos nós não encontramos lá porque eles olham cada observador no rosto; pelo contrário, o mundo é apresentado em um fluxo caleidoscópico de impressões que tem de ser organizado pelas nossas mentes, e isso significa, em grande medida, pelos sistemas linguísticos em nossas mentes. [...] nenhum indivíduo é livre para descrever a natureza com imparcialidade absoluta, mas é restrito a certos modos de interpretação

8 Original: "because of the tyrannical hold that linguistic form has upon our orientation in the world" (SAPIR, 1931, p. 28).

9 Original: "No two languages are ever sufficiently similar to be considered as representing the same social reality. The worlds in which different societies live are distinct worlds, not merely the same world with different labels attached." (SAPIR, 1929, p. 162). 
mesmo quando ele se considera mais livre. ${ }^{10}$ (WHORF, 1956, p. 213214, tradução nossa).

Na década 1950, mais de 20 anos depois da morte de Sapir e mais de 10 após a morte de Whorf, os psicólogos Roger Brown e Eric Lenneberg, dentre outros pesquisadores, buscaram revisar as ideias de Sapir e Whorf e traduzi-las em hipóteses testáveis cientificamente. Daí surgiu o que hoje conhecemos como a Hipótese Sapir-Whorf. O que se estabeleceu foi uma dicotomia em forma de duas versões da hipótese, uma "forte" e outra "fraca" (BROWN; LENNEBERG, 1954).

A versão "forte", conhecida como Determinismo Linguístico, afirma que "categorias variáveis da língua basicamente controlam as categorias da cognição geral" (PEDERSON, 2007, p. 1012, tradução nossa). Ou seja, a língua que falamos determina a forma como pensamos. Por seus argumentos, Edward Sapir e Benjamin Lee Whorf são comumente associados a essa visão determinista e até um tanto radical da relação entre língua e pensamento.

O Determinismo Linguístico acabou caindo em descrédito na comunidade científica. Ainda que haja diferenças conceituais entre culturas por causa de suas línguas, isso não significa que as diferenças sejam tão grandes a ponto de a compreensão mútua ser impossível. Além disso, o fato de uma língua não ter uma determinada palavra não significa que seus falantes não consigam compreender o conceito por trás dela (CRYSTAL, 2010).

A versão "fraca" da hipótese, também chamada Relativismo Linguístico, postula que "as categorias linguísticas podem influenciar as categorias do pensamento, mas não são fundamentalmente restritivas"12 (PEDERSON, 2007, p. 1012-1013, tradução nossa). Essa versão é uma interpretação mais branda do argumento whorfiano, defendida por pesquisas realizadas a partir dos anos 1980 (LAKOFF, 1987; LUCY, 1992; SLOBIN, 1996). Segundo Jarvis e Pavlenko (2010), esses estudos mostram que os que criticam a Hipótese Sapir-Whorf simplificaram demais e interpretaram mal as afirmações originais de Sapir e Whorf sobre como a língua influencia o pensamento, presumindo erradamente que eles acreditavam que a língua determina estritamente o pensamento.

O Relativismo Linguístico (i.e. a versão "fraca" ou branda da Hipótese Sapir-Whorf) engloba duas noções principais: (1) as línguas diferem significativamente uma das outras; (2) as línguas podem influenciar sistematicamente a forma como seus falantes

10 Original: "We dissect nature along lines laid down by our native languages. The categories and types that we isolate from the world of phenomena we do not find there because they stare every observer in the face; on the contrary, the world is presented in a kaleidoscopic flux of impressions which has to be organized by our minds - and this means largely by the linguistic systems in our minds. [...] no individual is free to describe nature with absolute impartiality, but is constrained by certain modes of interpretation even when he thinks himself most free." (WHORF, 1956, p. 213-214).

11 Original: "variable categories of language essentially control the available categories of general cognition" (PEDERSON, 2007, p. 1012).

12 Original: "the linguistic categories may influence the categories of thought but are not fundamentally restrictive" (PEDERSON, 2007, p. 1012-1013). 
pensam (SWOYER, 2011; WOLFF; HOLMES, 2011). Para Swoyer, a primeira noção é incontestável, pois

[...] ainda que todas as línguas humanas compartilhem numerosos universais linguísticos abstratos, frequentemente há grandes diferenças em suas estruturas sintáticas e seus léxicos, como qualquer um que tenha aprendido uma segunda língua pode atestar. ${ }^{13}$ (SWOYER, 2011, p. 25, tradução nossa).

Já a segunda afirmação, para o autor, ainda que um tanto quanto controversa, é plausível, mas para que seja testável, é preciso que a pesquisa sobre o Relativismo Linguístico se concentre em questões mais específicas, tais como: "1. Quais aspectos da língua influenciam quais aspectos do pensamento de uma forma sistemática? 2. Que forma essa influência toma? 3. Quão forte é a influência?"14 (SWOYER, 2011, p. 25, grifos do autor, tradução nossa).

É justamente isso que têm feito as pesquisas mais modernas sobre a questão. Os pesquisadores têm investigado os efeitos da língua sobre a cognição em domínios conceituais específicos. Jarvis e Pavlenko (2010) listam oito domínios em que já existem pesquisas com conclusões importantes: objetos, emoções, pessoa, gênero, número, tempo, espaço e movimento. A título de exemplificação, mencionamos, a seguir, um estudo para cada um desses domínios:

a. Objetos: A pesquisa de Malt, Sloman e Gennari (2003) e Malt et al. (1999) mostrou que os 16 objetos chamados bottle (garrafa) em inglês são separados em sete categorias linguísticas em espanhol. Isso significa que falantes de inglês-LM que sejam aprendizes de espanhol precisam formar novas categorias conceituais com propriedades específicas que não são contempladas por sua LM, por exemplo, a distinção entre as garrafas para líquidos e as para sólidos.

b. Emoções: Pavlenko (2002) mostrou que ainda que o inglês e o russo expressem emoções tanto com verbos quanto com adjetivos, essas línguas diferem quanto a qual tipo de estrutura tem dominância. Em um experimento no qual monolíngues de cada língua relataram suas impressões sobre um mesmo curta-metragem, os falantes de inglês descreveram emoções usando mais adjetivos (e, portanto, percebendo-as como estados), enquanto que os falantes de russo usaram mais verbos para se referirem às mesmas emoções (considerando-as, portanto, processos).

13 Original: "even if all human languages share numerous abstract linguistic universals, there are often large differences in their syntactic structures and their lexicons, as anyone who has learned a second language can attest" (SWOYER, 2011, p. 25).

14 Original: "1. Which aspects of language influence which aspects of thought in a systematic way? 2. What form does this influence take? 3. How strong is the influence?" (SWOYER, 2011, p. 25, italics by the author). 
c. Pessoa: A forma como cada língua categoriza gramatical e lexicalmente o conceito de "pessoa" pode variar substancialmente. Por exemplo, o francês, o russo e o alemão codificam a relação (de hierarquia, diferença de idade, status social, grau de intimidade, etc.) entre o falante e seu interlocutor através do pronome da $2^{\mathrm{a}}$ pessoa do singular (em alemão, $d u$ ou Sie). Para aprender a selecionar pronomes adequadamente em alemão, um aprendiz falante nativo de uma língua que não faz essa distinção terá de fazer muito mais do que simplesmente memorizar pronomes: ele terá que adquirir novas formas de conceber seus interlocutores (BARRON, 2006).

d. Gênero: Um dos experimentos do estudo de Boroditsky, Schmidt e Phillips (2003) mostrou que falantes de línguas que marcam gênero gramaticalmente são influenciados em suas percepções sobre substantivos inanimados pelo gênero gramaticalmente atribuído a eles. Por exemplo, ao descreverem em inglês-L2 uma chave, ${ }^{15}$ um nome feminino em espanhol (la llave) e masculino em alemão (der Schlüssel), os falantes de espanhol-LM utilizaram adjetivos como little, lovely, shiny, enquanto os falantes de alemão-LM descreveram o objeto com adjetivos como hard, heavy e metal.

e. Número: Lucy (1992) demonstrou que os falantes de línguas que marcam número morfossintaticamente (ex.: inglês) e os que falam línguas que não fazem essa marcação (ex.: yucatec) podem diferir no seu grau de atenção ao número de objetos ao descreverem uma situação.

f. Tempo: O inglês tende a representar duração temporal sobre uma distância linear (a long time) enquanto que o espanhol concebe o tempo como quantidade (mucho tiempo). Essa diferença afeta a cognição não-verbal: falantes dessas línguas diferem significativamente em tarefas de estimação de tempo (CASASANTO et al., 2004).

g. Espaço: Relações espaciais que em inglês são codificadas linguisticamente com a preposição on, em holandês requerem três preposições: op, aan e om (BOWERMAN, 1996). Essa diferença representa uma dificuldade à parte para aprendizes de holandês-L2 falantes de inglês-LM, que terão que formar três novas categorias em sua interlíngua para dar conta das diferentes conceitualizações de espaço do holandês que não existem em sua LM.

h. Movimento: Berman e Slobin (1994) demonstraram que narrativas sobre um livro de figuras obtidas de falantes de línguas satellite-framed como o inglês (que, para descrever eventos de movimento, codifica modo no verbo e caminho/ trajetória em advérbios e preposições - ex.: they ran into the house) contêm mais detalhes sobre padrões motores, velocidade e qualidade dos movimentos do que as narrativas feitas por falantes de línguas verb-framed, como o espanhol (que codifica a trajetória no verbo e, opcionalmente, modo em outro verbo, no gerúndio - ex.: entraron corriendo a la casa).

15 Key em inglês, uma língua que não marca gênero dos nomes gramaticalmente. 
Grande parte das pesquisas sobre o Relativismo Linguístico no século XX se concentraram na investigação das categorias gramaticais e conceituais de falantes monolíngues de línguas distantes. Entre os anos 1950 e 1990, por causa do advento da agenda gerativista de Chomsky e do desenvolvimento da pesquisa sobre universais linguísticos, o Relativismo Linguístico acabou sendo marginalizado e esquecido na Academia. Entretanto, os últimos 30 anos viram um ressurgimento do interesse acadêmico sobre o assunto, principalmente com os avanços das pesquisas em Cognição, Psicolinguística e Neurolinguística. De um viés monolíngue, a pesquisa sobre a influência das línguas sobre o pensamento passou a ter um enfoque bilíngue, como veremos na próxima seção.

\section{Transferência conceitual: a virada bilíngue na pesquisa sobre o Relativismo Linguístico}

A pesquisa sobre transferência, como vimos na segunda seção deste trabalho, tipicamente trata de analisar e descrever como a compreensão ou o uso de uma língua que se está aprendendo podem ser influenciados pelos conhecimentos prévios que se tem de outra(s) língua(s). Ou seja, busca-se explicar tal influência em termos de "semelhanças e diferenças entre as propriedades estruturais da língua-fonte e da língua-receptora" (JARVIS; PAVLENKO, 2010, p. 112). Na terceira seção, mostramos que as pesquisas mais recentes sobre o Relativismo Linguístico têm evidenciado diferenças entre as línguas também no nível da organização de domínios conceituais. No entanto, a maioria dos estudos, como os mencionados naquela seção, estabelecem essas dessemelhanças através da comparação entre falantes monolíngues de cada língua. Aqui cabe uma pergunta: o que o Relativismo Linguístico teria a ver com a aprendizagem de L2? Ou, mais especificamente, poderiam essas diferenças translinguísticas conceituais também afetar o desempenho do aprendiz de L2 na língua que ele está aprendendo?

Desde o início da pesquisa em bilinguismo, com o trabalho de Weinreich (1953), tem-se buscado explicar como se dá a conexão entre as diferentes estruturas e formas de uma língua e suas representações conceituais na mente do bilíngue. Diversas hipóteses foram propostas e, a partir delas, vários modelos de representação mental do léxico foram desenvolvidos.

Os primeiros modelos partiam do pressuposto de que a representação conceitual é compartilhada entre as línguas, ainda que haja várias representações formais para um dado conceito. Desse modo, as palavras cat e gato teriam exatamente o mesmo significado, isto é, estariam ligadas a um mesmo conceito - o de "animal doméstico que mia”. O Modelo Hierárquico Revisado (KROLL; STEWARD, 1994) é provavelmente o mais famoso a representar tal hipótese (Fig. 2). Segundo esse modelo, existem conexões entre as formas da L1 e da L2 e entre elas e representações conceituais compartilhadas. Entretanto, a conexão entre L2 e L1 é mais forte do que a conexão entre L2 e os conceitos, e a conexão entre a L1 e os conceitos é a mais forte de todas. 
Assim, o aprendiz de L2 acessaria a maioria dos conceitos em L2 através da L1 (transferência linguística), e a aprendizagem de L2 sem a influência da L1 dependeria do fortalecimento da conexão direta das formas dessa língua com as representações conceituais, as quais ele já teria, pois seriam as mesmas da L1.

Figura 2 - O Modelo Hierárquico Revisado.

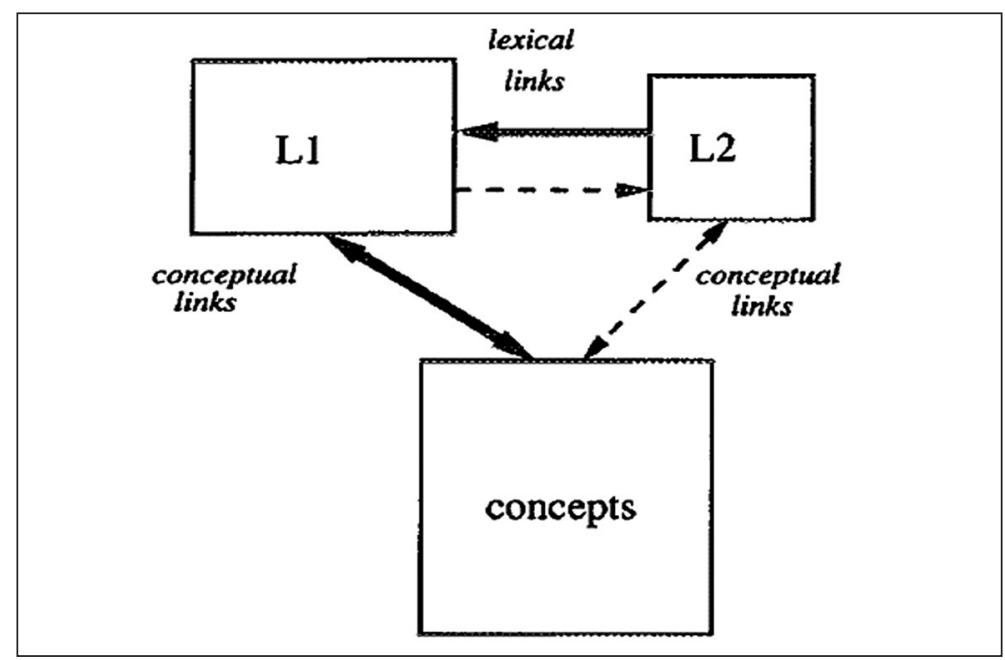

Fonte: Kroll e Steward (1994, p.158).

O Modelo Hierárquico Revisado não explica o caso de pares de palavras que não compartilham todos os significados, isto é, onde não há total equivalência conceitual entre as palavras (ex.: ambas as palavras cat e gato significam "animal doméstico que mia", mas apenas a palavra gato também quer dizer "alguém que é fisicamente atraente" ou "prolongamento ilegal de um ponto de fornecimento de energia elétrica"). Para tentar dar conta dos significados específicos que muitas palavras têm em determinada língua mas não em outra, foram propostos modelos como o da Característica Conceitual Distribuída (DE GROOT, 1993), que não vê os conceitos como unidades estanques na memória, mas como representações "distribuídas", em que cada conceito é, na verdade, um conjunto de atributos conceituais mais elementares. De acordo com esse modelo (Fig. 3), entre duas línguas há pares de palavras que compartilham mais características conceituais e outros que compartilham menos. 
Figura 3 - O Modelo de Característica Conceitual Distribuída.

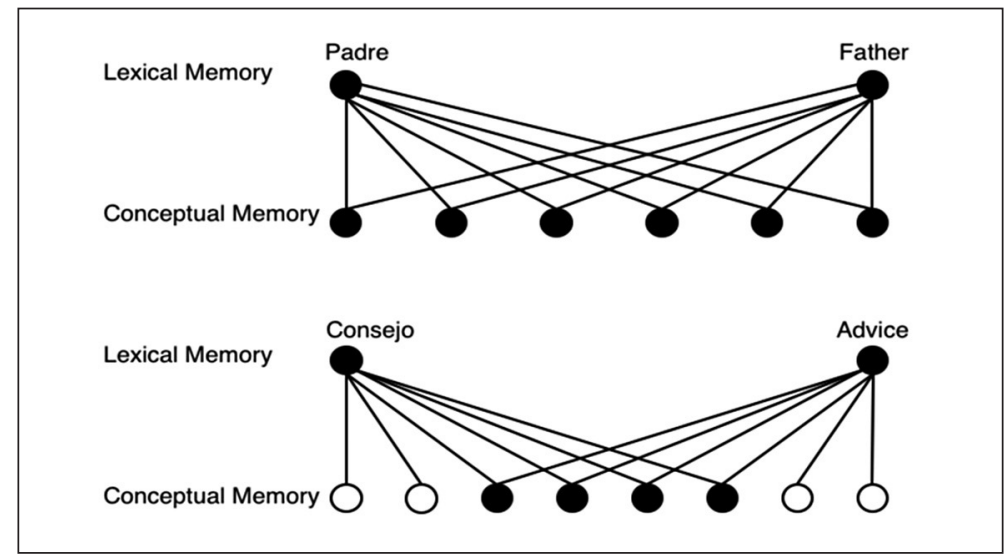

Fonte: Adaptado de De Groot (1993).

Os estudos mais atuais sobre o Relativismo Linguístico têm indicado que há conceitos que existem em certas línguas, mas não em outras. Por exemplo, ao comparar narrativas de monolíngues de russo e inglês, Pavlenko (2003) concluiu que a língua russa não só não possui equivalentes para a palavra inglesa privacy (privacidade), como também não tem o próprio conceito de privacidade. A virada bilíngue que mencionamos no título da presente seção diz respeito ao fato de as investigações estarem deixando de ser sobre a análise do desempenho do falante nativo monolíngue da língua $\mathrm{A}$ em comparação com a do falante nativo monolíngue da língua B para se dedicarem a analisar como bilíngues falantes das línguas A e B categorizam e expressam a sua experiência no mundo quando certos conceitos das suas línguas não são equivalentes. No mesmo estudo mencionado acima, Pavlenko observou que, ao relatarem em russo uma cena de vídeo que mostrava uma situação que poderia ser potencialmente percebida como invasão de privacidade, bilíngues russo-LM/inglês-L2 residentes nos Estados Unidos se utilizaram de code-switching e empréstimos lexicais para expressar o conceito em questão, enquanto que bilíngues russo-LM/inglês-LE que nunca estiveram num país anglófono jamais comentaram sobre a proximidade espacial entre os personagens do vídeo, nem mesmo ao mais tarde relatarem a cena em inglês. A autora concluiu que o contato mais intenso e prolongado com a língua e a cultura anglófona fez com que os bilíngues residentes nos EUA adquirissem o conceito de privacidade da língua inglesa. O segundo grupo de bilíngues, com menos contato com a LE e nenhuma experiência real com a sua cultura, não tiveram a oportunidade ou a necessidade de adquirir o conceito.

Outros estudos com bilíngues e/ou aprendizes de L2/LE mostraram que quando há uma equivalência parcial entre os conceitos das línguas em contato na sua mente, os bilíngues frequentemente desenvolvem sua própria representação conceitual, que diverge daquela de monolíngues de cada língua. Podemos citar o exemplo da equivalência parcial entre inglês e russo em certos itens do domínio das cores. Em 
inglês, a categoria blue inclui o que em russo são duas categorias: goluboy (azul claro, aproximadamente) e siniy (azul escuro, aproximadamente) (Fig. 4) (ANDREWS, 1994; WINAWER et al., 2007).

Figura 4 -As duas cores russas para o inglês blue.

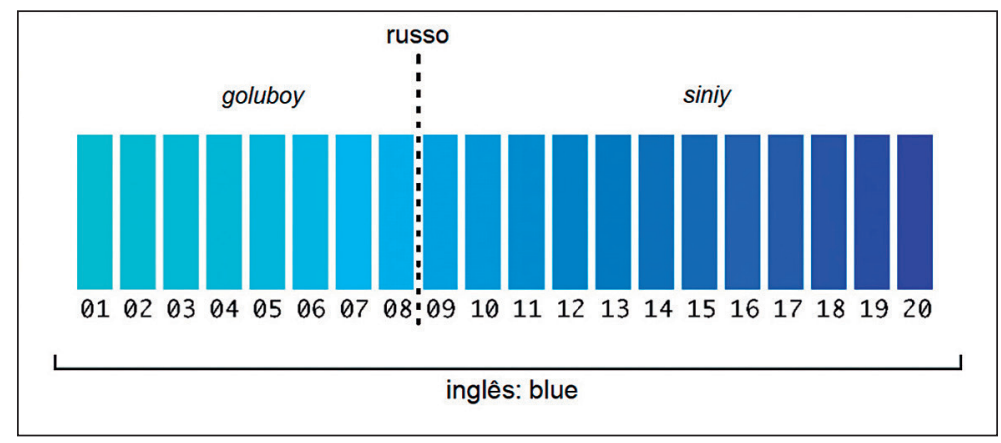

Fonte: Adaptado de Winawer et al. (2007).

Andrews (1994) mostrou que bilíngues russo-LM/inglês-L2 que moravam nos Estados Unidos e tinham inglês como língua dominante estavam perdendo a distinção entre siniy e goluboy, passando a utilizar, ao falarem russo, a palavra goluboy em contextos em que se esperaria que usassem siniy. Essa influência do significado que uma palavra ou estrutura tem numa língua sobre a compreensão ou uso de uma palavra ou estrutura equivalente noutra língua (que nessa outra língua está ligada a um conceito distinto) é o que os pesquisadores chamam de transferência conceitual.

Baseando-se nos achados de estudos com bilíngues como os recém citados, Pavlenko (2009) propôs um novo modelo de representação do léxico bilíngue, o Modelo Hierárquico Modificado (Fig. 5), para representar três aspectos não contemplados em modelos anteriores: (1) a existência não apenas de conceitos equivalentes e conceitos (parcialmente) compartilhados entre as línguas, mas também de conceitos que são específicos de uma das línguas; (2) o fenômeno da transferência conceitual, em que certo conteúdo conceitual exclusivo de uma língua é atribuído a uma palavra de outra língua; e (3) a ideia de aprendizagem de LE como reestruturação conceitual, ou seja, um processo gradual no qual o aprendiz vai reformulando suas categorizações conceituais de forma que elas cheguem o mais próximo possível da representação conceitual do falante nativo da língua-alvo - uma versão "cognitivo-conceitual" e whorfiana da teoria da Interlíngua de Selinker (1972). 
Figura 5 - O Modelo Hierárquico Modificado.

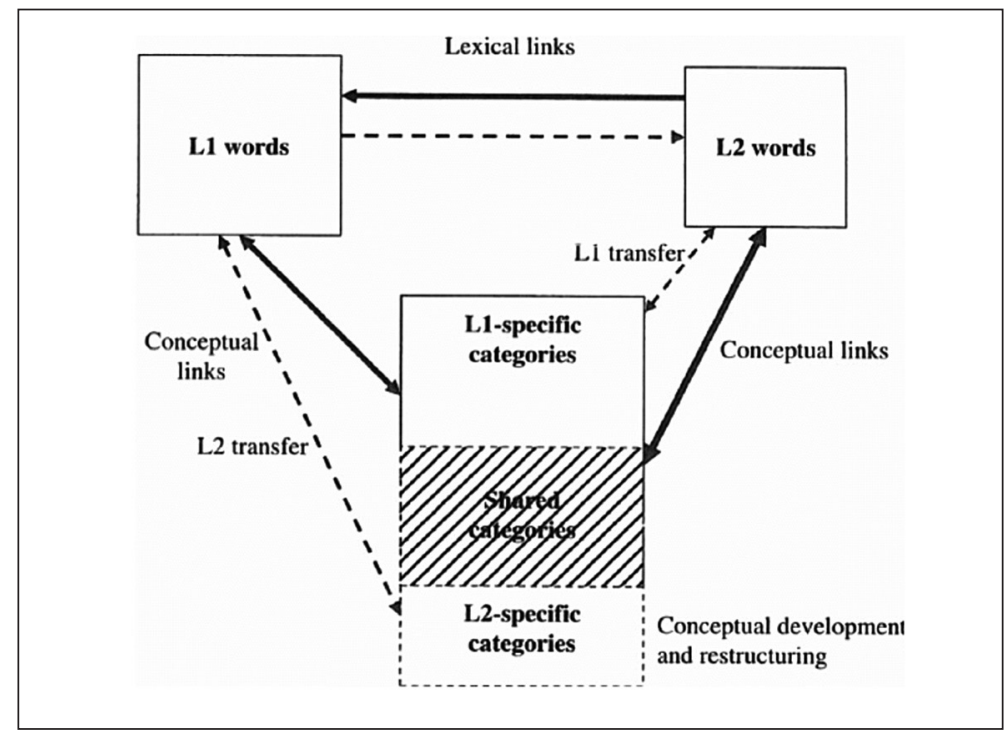

Fonte: Pavlenko (2009, p.147).

O Modelo Hierárquico Modificado foi claramente desenvolvido sobre o design do Modelo Hierárquico Revisado, mas difere dele principalmente pela sua seção inferior, que ilustra a estrutura da representação conceitual na mente bilíngue. Para Pavlenko (2009), há três tipos de relação de equivalência conceitual bilíngue.

Na primeira, a equivalência conceitual, elementos lexicais ou gramaticais de duas línguas compartilham a mesma representação conceitual. $\mathrm{O}$ efeito dessa equivalência na aprendizagem de L2 é a facilitação da transferência positiva - o aprendiz precisará estabelecer conexões entre palavras da L2 e conceitos já existentes. Em um dos estudos a evidenciarem esse efeito, Pavlenko (2008) pediu a falantes nativos monolíngues de inglês e russo que assistissem a um curta-metragem e o descrevessem. Ao se referirem ao sentimento de medo de um dos personagens, os falantes de russo-L1 usaram verbos reflexivos tais como ispugat'sia (assustar-se) e boiat'sia (ter medo), e os falantes de inglês-L1 utilizaram adjetivos ou particípios como afraid (com medo), frightened (assustado) e terrified (aterrorizado). Ou seja, ainda que de categorias gramaticais diferentes, as palavras russas e inglesas se referiam ao mesmo domínio conceitual "medo". A equivalência conceitual foi confirmada quando o estudo se voltou a falantes de inglês-L1/russo-L2 e de russo-L1/inglês-L2: as narrativas produzidas por eles, a partir do mesmo curta-metragem, mostraram que as suas escolhas lexicais em L2 foram em grande parte as mesmas dos monolíngues.

Na segunda relação, a equivalência parcial, há uma sobreposição dos limites da representação conceitual de certo elemento em cada língua, e apenas parte dela é compartilhada. Neste tipo de relação ocorre o que a autora chama de aninhamento 
(nesting), isto é, quando uma categoria de uma língua é dividida em duas em outra língua, ou quando uma categoria de uma língua absorve (parcial ou integralmente) duas ou mais categorias de outra língua. Neste caso, a sobreposição parcial facilita a aprendizagem (transferência positiva), mas também pode dificultá-la quando o aprendiz presume equivalência completa onde não há (transferência negativa). Esse seria o caso, entre inglês e português, dos pares cat/gato e guitar/guitarra, mencionados anteriormente. Aqui, para ter sucesso na aprendizagem de determinado item lexical ou gramatical, o aprendiz precisará reestruturar suas representações conceituais.

No terceiro tipo de relação, o de não-equivalência, uma categoria conceitual de uma língua não tem correspondente direto na outra língua. Isso dificulta a aprendizagem, pois o aprendiz terá que criar novas categorias, mas também a facilita através a ausência de representações conflitantes. A não-equivalência conceitual foi demonstrada na pesquisa sobre o conceito de privacidade feita por Pavlenko (2002) e descrita acima nesta seção.

Ao incluir em seu o modelo esses três tipos de relações de equivalência conceitual, Pavlenko não só consegue explicar como se dá o desenvolvimento da interlíngua no nível dos conceitos, como também elucida os achados de vários estudos sobre a influência translinguística, como os mencionados na seções anteriores, corroborando o pressuposto de que as línguas que falamos podem, de fato, influenciar a forma como categorizamos e fazemos sentido da nossa experiência no mundo.

\section{Conclusão}

Com esta revisão teórica, buscamos, ainda que de forma breve, através da discussão de conceitos e hipóteses de estudos considerados como referência nas áreas em questão, estabelecer as intersecções entre a pesquisa sobre a transferência, o Relativismo Linguístico e a Aprendizagem de L2. Retomamos, a seguir, os principais pontos abordados.

A transferência é, como propôs Selinker(1972), parte do processo de desenvolvimento da interlíngua, ou seja, é um fenômeno indissociável da aprendizagem de L2. Durante a segunda metade do século XX, a pesquisa sobre o fenômeno se concentrou naquilo que hoje podemos chamar de transferência linguística, isto é, a influência de aspectos formais de uma língua sobre a compreensão e uso de aspectos formais de outra, influência essa que se manifesta nos vários âmbitos da língua, tais como sintaxe, morfologia, fonologia, semântica etc. (ODLIN, 1989). Estudos mais recentes, dos últimos 20 anos, têm demonstrado que o fenômeno da transferência também pode se manifestar na forma de influências translinguísticas no nível conceitual, ou seja, quando conceitos de uma língua sem equivalência ou com equivalência parcial em outra afetam a compreensão e uso desta - um fenômeno que os pesquisadores chamam de transferência conceitual (PAVLENKO, 2009).

Os achados sobre a transferência conceitual advêm de estudos sobre a cognição bilíngue, isto é, sobre como os bilíngues fazem sentido do mundo a sua volta e 
como expressam, nas suas diferentes línguas, a sua experiência nele. É uma área de investigação que se apoia em diversos paradigmas e teorias, dentre as quais se destacam a teoria da Interlíngua (SELINKER, 1972), sobre o processo de desenvolvimento dos conhecimentos de L2 na mente do aprendiz, e a hipótese do Relativismo Linguístico (LUCY, 1992), sobre a influência das línguas que falamos sobre a forma como pensamos.

Como discutimos na terceira e quarta seções, a pesquisa sobre a influência das línguas na cognição dos seus falantes - ou Relativismo Linguístico -, que durante muito tempo se concentrou na comparação de falantes monolíngues de línguas distintas, e que até o início do século XXI se encontrava em desprestígio na Academia, ganhou uma nova leva de evidências a seu favor quando estudiosos do bilinguismo começaram a desvelar a natureza daquilo que hoje chamamos de transferência conceitual (JARVIS; PAVLENKO, 2010). A existência de um fenômeno de influência translinguística no nível dos conceitos, através do qual o aprendiz de L2 incorpora significados e categorizações de uma língua no uso de outra, que não tenha tais conceitos ou os categorize de maneira diferente, corrobora a premissa central do Relativismo Linguístico - a de que diferenças conceituais entre as línguas poderiam afetar a forma como os seus falantes veem o mundo.

No entanto, a pesquisa sobre a cognição bilíngue já está indo mais além. Já se sabe, por exemplo, que o bilíngue pode formar suas próprias categorias conceituais, que divergirão daquelas de falantes monolíngues das línguas que ele fala (PAVLENKO, 2014; DE GROOT, 2013). A aprendizagem de L2 envolveria, portanto, não apenas o estabelecimento de conexões entre as formas, os significados e as funções da L2 com o conhecimento linguístico prévio do aprendiz, mas também uma reestruturação das representações conceituais em sua mente. Para Pavlenko (2009), a transferência conceitual seria evidência dessa reestruturação e, por conseguinte, da hipótese do Relativismo Linguístico.

No futuro, mais pesquisas com bilíngues, tanto os com mais de uma LM quanto os que estejam aprendendo ou tenham aprendido uma língua após sua(s) LM(s), poderão elucidar questões que ainda carecem de investigação, tais como: Como a transferência conceitual pode ser prevista? Quais fatores afetam mais ou menos a ocorrência da transferência conceitual? Quais são as implicações dos achados sobre a cognição bilíngue e o Relativismo Linguístico para o ensino de segunda língua e língua estrangeira? Independentemente das abordagens e dos rumos que a pesquisa tomar daqui para a frente, essas questões, assim como todo percurso da pesquisa sobre transferência, indicam que o estudo da cognição bilíngue parece ser o caminho para compreendermos como as línguas que falamos influenciam o modo como pensamos. 
FERREIRA, R. C.; MOZZILLO, I.. Conceptual transfer: linguistic relativity in second language learning. Alfa, São Paulo, v.65, 2021.

- ABSTRACT: The influence of a language on the learning of another, or language transfer, has been extensively investigated in the field of Second Language Acquisition. There are, however, studies on a kind of transfer that occurs in the level of conceptual categorizations and that supports the hypothesis of the influence of language on cognition, or Linguistic Relativity. This phenomenon, known as conceptual transfer (JARVIS and PAVLENKO, 2010), is the object of this theoretical literature review. First, we revisit the development of the research on cross-linguistic influence, from the earlier studies, which considered it something negative for second language learning, to the latest ones, which show various effects, including facilitation. We then approach Linguistic Relativity, also known as the Sapir-Whorf Hypothesis, recalling what was postulated by its classic authors and by more recent researchers, which have reformulated the hypothesis. Finally, we review the most preeminent models of representation of the bilingual mental lexicon up to Pavlenko's (2009), which explains conceptual transfer and brings Linguistic Relativity closer to Second Language Acquisition. The review ends with the claim that the research on bilingual cognition, through the investigation of conceptual transfer, may show how the languages we speak influence our cognition.

- KEYWORDS: Conceptual transfer. Cross-linguistic influence. Sapir-Whorf Hypothesis. Linguistic Relativity. L2 learning. Bilingualism.

\section{REFERENCES}

ANDREWS, D. The Russian Color Categories Sinij and Goluboj: An Experimental Analysis of Their Interpretation in the Standard and Emigré Languages. Journal of Slavic Linguistics, Nova Gorica, v. 2, n. 1, p. 9-28, 1994.

ARABSKI, J. (org.). Cross-linguistic influences in the second language lexicon. Clevedon: Multilingual Matters, 2006.

BARRON, A. Learning to Say "You" in German: The Acquisition of Sociolinguistic Competence in a Study Abroad Context. In: DUFON, M.; CHURCHILL, E. (org.). Language Learners in Study Abroad Contexts. Clevedon: Multilingual Matters, 2006. p. 59-88.

BERMAN, R.; SLOBIN, D. Relating events in narrative: A crosslinguistic developmental study. Mahwah, NJ: Erlbaum, 1994.

BOAS, F. The Methods of Ethnology. American Anthropologist, Arlington, v.22, n.4, p.311-321, 1920 .

BORODITSKY, L.; SCHMIDT, L.; PHILLIPS, W. Sex, syntax, and semantics. In: GENTNER, D.; GOLDIN-MEADOW, S. (ed.). Language in mind: Advances in the study of language and thought. Cambridge, MA: MIT Press, 2003. p. 61-79. 
BOWERMAN, M. Learning how to structure space for language: A crosslinguistic perspective. In: BLOOM, P.; PETERSON, M.; NADEL, L.; GARRETT, M. (ed.). Language and space. Cambridge, MA: MIT Press, 1996. p. 385-436.

BROWN, R.; LENNEBERG, E. A study in language and cognition. The Journal of Abnormal Psychology, Washington, v. 49, n. 3, p. 454-462, 1954.

CASASANTO, D.; BORODITSKY, L.; PHILLIPS, W.; GREENE, J.; GOSWAMY, S.; BOCANEGRA-THIEL, S.; SANTIAGO-DIAZ, I.; FOTOKOPOULU, O.; PITA, R.; GIL, D. How deep are effects of language on thought?: Time estimation in speakers of English, Indonesian, Greek, and Spanish. In: ANNUAL CONFERENCE OF THE COGNITIVE SCIENCE SOCIETY, 26., Chicago, IL. Proceedings [...], Chicago, 2004. p.186-191.

CENOZ, J.; HUFEISEN, B.; JESSNER, U. (ed.). Cross-linguistic influence in third language acquisition: Psycholinguistic perspectives. Clevedon, UK: Multilingual Matters, 2001.

CRYSTAL, D. The Cambridge Encyclopedia of Language. 3. ed. Cambridge: Cambridge University Press, 2010.

DE GROOT, A.M.B. The bilingual memory. In: GROSJEAN, F.; LI, P. (org.). The psycholinguistics of bilingualism. Chichester: Wiley-Blackwell, 2013. p. 171-191.

DE GROOT, A.M.B. Word-Type Effects in Bilingual Processing Tasks: Support for a mixed-Representational System. In: SCHREUDER, R.; WELTENS, B. (org.). Studies in Bilingualism. Amsterdam: John Benjamins, 1993. p. 27-51.

FRIES, C. Teaching and learning English as a foreign language. Ann Arbor: University of Michigan Press, 1945.

JANSE. Aspects of Bilingualism in the History of the Greek Language. In: ADAMS, J., JANSE, M.; SWAIN, S. Bilingualism in Ancient Society. Oxford: Oxford University Press, 2002. p. 332-390.

JARVIS, S. Methodological rigor in the study of transfer: identifying L1 influence in the interlanguage lexicon. Language learning, Medford, v. 50, n. 2, p. 245-309, 2000.

JARVIS, S.; PAVLENKO, A. Crosslinguistic influence in language and cognition. New York: Routledge, 2010.

JESPERSEN, O. Language: its nature, development and origin. London: G. Allen \& Unwin, 1922.

KELLERMAN, E. Towards a characterisation of the strategy of transfer in second language learning. Interlanguage Studies Bulletin, Bristol, v. 2, n. 1, p. 58-145, 1977.

KELLERMAN, E.; SHARWOOD-SMITH, M. Crosslinguistic influence in second language acquisition. Oxford: Pergamon Press, 1986. 
KROLL, J.; STEWART, E. Category Interference in Translation and Picture Naming: Evidence for Asymmetric Connections Between Bilingual Memory Representations. Journal of Memory and Language, London, v. 33, n. 2, p. 149-174, 1994.

LADO, R. Linguistics across cultures: applied linguistics for language teachers. Ann Arbor: University of Michigan Press, 1957.

LAKOFF, G. Women, fire, and dangerous things: What categories reveal about the mind. Chicago: University of Chicago Press, 1987.

LUCY, J. Language diversity and thought: A reformulation of the linguistic relativity hypothesis. Cambridge, UK: Cambridge University Press, 1992.

MALT, B.; SLOMAN, S.; GENNARI, S. Universality and language specificity in object naming. Journal of Memory and Language, v. 29, p. 20-42, 2003.

MALT, B.; SLOMAN, S.; GENNARI, S.; SHI, M.; WANG, Y. Knowing versus naming: Similarity and the linguistic categorization of artifacts. Journal of Memory and Language, v. 40, p. 230-262, 1999.

ODLIN, T. Cross-linguistic influence. In: DOUGHTY, C. J.; LONG, M. H. (org.). The handbook of second language acquisition. Oxford: Blackwell Publishing, 2003. p. 436-486.

ODLIN, T. Transferability and lexical restructuring (or: what gets lost in the translation-and why?). In: BLACKSHIRE-BELAY, C. Current Issues in Second Language Acquisition and Development. Lanham: University Press of America, 1994. p. 29-45.

ODLIN, T. Language transfer: cross-linguistic influence in language learning. Cambridge: Cambridge University Press, 1989.

PAVLENKO, A. The bilingual mind: and what it tells us about language and thought. Cambridge; New York: Cambridge University Press, 2014.

PAVLENKO, A. The Bilingual Mental Lexicon: Interdisciplinary Approaches. Clevedon: Multilingual Matters, 2009.

PAVLENKO, A. Structural and conceptual equivalence in the acquisition and use of emotion words in a second language. The Mental Lexicon, Amsterdam, v. 3, n. 1, p. 91-120, 2008.

PAVLENKO, A. Eyewitness memory in late bilinguals: Evidence for discursive relativity. International Journal of Bilingualism, v. 7, n. 3, p. 257-281, 2003.

PAVLENKO, A. Bilingualism and emotions. Multilingua, v. 21, p. 45-78, 2002.

PEDERSON, E. Cognitive Linguistics and Linguistic Relativity. In: GEERAERTS. D.; CUYCKENS, H. The Oxford Handbook of Cognitive Linguistics. Oxford: Oxford University Press, 2007. p. 1012-1044. 
RINGBOM, H. Cross-linguistic similarity in foreign language learning. Clevedon: Multilingual Matters, 2007.

RINGBOM, H. On learning related and unrelated languages. Moderna språk, Stockholm, v. 72, p. 21-25, 1978.

SAPIR, E. Language: An Introduction to the Study of Speech. Chelmsford: Courier Corporation, 2004. Original de 1921.

SAPIR, E. Conceptual categories in primitive languages. Science, Washington, v. 74, p. 578, 1931.

SAPIR, E. The status of linguistics as a science. Language, Washington, v. 5, p. 207-214, 1929.

SCHACHTER, J.; RUTHERFORD, W. Discourse function and language transfer. Working Papers in Bilingualism, Ontario, v. 19, p. 3-12, 1979.

SELINKER, L. Interlanguage. International Review of Applied Linguistics in Language Teaching, Berlin, v. 10, n. 1-4, p. 209-232, 1972.

SJÖHOLM, K. The influence of crosslinguistic, semantic, and input factors on the acquisition of English phrasal verbs: a comparison between Finnish and Swedish learners at an intermediate and advanced level. Åbo: Åbo Akademi University Press, 1995.

SLOBIN, D. From "thought and language" to "thinking for speaking". In: GUMPERZ, J; LEVINSON, S. (ed.). Rethinking linguistic relativity. Cambridge, UK: Cambridge University Press, 1996. p. 70-96.

SWOYER, C. How does language affect thought? In: COOK, V.; BASSETTI, B. (ed.). Language and Bilingual Cognition. Hove: Psychology Press, 2011. p. 23-42.

WEINREICH, U. Languages in contact: findings and problems. The Hague: Mouton, 1953.

WINAWER, J.; WITTHOFT, N.; FRANK, M. C.; BORODITSKY, L. Russian blues reveal effects of language on color discrimination. Proceedings of the National Academy of Sciences, Washington, v. 104, n. 19, p. 7780-7785, 2007.

WHORF, B. Language, thought, and reality. New York: Wiley, 1956.

WOLFF P.; HOLMES K. Linguistic relativity. WIREs Cognitive Science, Hoboken, v. 2, p. $253-265,2011$.

Recebido em 28 de julho de 2019

Aprovado em 28 de julho de 2020 